DOI:

\title{
CASE MORPHEMIZATION AS THE BASIS OF ITS VIEWING WITHIN A COGNITIVE TYPOLOGICAL MODEL
}

\author{
Alexey B. Chernyshev \\ Candidate of Philological Sciences, Senior Teacher \\ Yaroslavl State Pedagogical University named after K. D. Ushinsky \\ (Yaroslavl, Russia) \\ e-mail: alexeich 78@mail.ru
}

\begin{abstract}
A problem of cases has been widely researched in linguistics. Formal and semantic approaches to the case study have been traditionally distinguished and are reviewed in the article. In this paper Dative is described as a cognitive-and-typological model with its internal meaning projected to the semantic structure of the language units. Actualization of Dative is shown on the material of languages having the different typological structure - English, Russian, Uzbek and Georgian. It is postulated that in the aforementioned languages such corresponding units as $t o, n p u, g a, \partial m$ can be considered Dative markers. The fact that these markers represent different elements of the word structure - preposition, prefix and affix - enables to make a conclusion about possibility of further researches in the field of a stage and system typology, with a word being associated with a «compressed» model of a sentence.
\end{abstract}

Keywords: typology, Dative, morpheme, model, movement

\section{МОРФЕМИЗАЦИЯ ПАДЕЖА КАК ОСНОВАНИЕ ВЫЯВЛЕНИЯ ЕГО КОГНИТИВНО- ТИПОЛОГИЧЕСКОЙ МОДЕЛИ}

\author{
Алексей Борисович Чернышев \\ Кандидат филологических наук, старший преподаватель \\ Ярославский государственный педагогический университет им. К. Д. Ушинского \\ (Ярославль, Россия) \\ e-mail: alexeich78@,mail.ru
}

\begin{abstract}
Аннотация. В данной работе датив описывается как когнитивно-типологическая модель с присущим ей внутренним значением, проецируемым в семантическую структуру конкретных языковых единиц. На материале разноструктурных языков показывается актуализация датива. Признается, что маркерами в соответствующих языках выступают $t o, n p u, g a, \partial m$. Тот факт, что данными маркерами являются разные элементы структуры слова - предлог, префикс, аффикс - позволяет сделать вывод о возможности дальнейших исследований в области стадиальной и системной типологии, ориентируясь на слово как на «сжатую» модель предложения.
\end{abstract}

Ключевые слова: типология, датив, морфема, модель, движение

Введение. Проблема падежей является одной из самых традиционных и широко изученных в лингвистике. Однако в свете сопоставительных и типологических исследований последних десятилетий с привлечением материала по ряду не изученных прежде - новых или экзотических - языков лингвисты вынуждены вновь обращаться к проблеме падежей, выявляя определенную противоречивость имеющихся данных и предлагая новые концепции, основывающиеся на понимании языкового типа и универсалий. Цель данной работы состоит в семантическом анализе конкретных языковых единиц, морфем, отражающих универсальную смысловую стратегию падежной категории датива, в английском, русском, узбекском и грузинском языках,

Формальный и семантический критерии выделения падежей в истории лингвистки. Среди множества направлений, имевших место в лингвистической теории падежей, представляется возможным выделить два основополагающих критерия к изучению падежей: формальный и семантический. Формальный подход связан с определением форм существительного, как правило, флексий, меняющихся в зависимости от синтаксической роли имени и его отношения к другим существительным и глаголам в структуре предложения. Однако склонение существительных по всевозможным падежам в языковой системе выглядело, очевидно, настолько незакономерным, что уже в 19 веке обозначились попытки семантического обоснования феномена падежа. Чешский и русский лингвист В. И. Шерцль одним из первых дал подробную классификацию значений всех падежей санскрита. Словенский языковед Ф. Миклошич впервые предложил разделение падежа и падежной формы, которое со временем легло в основу известнейшей падежной теории Ч. Филлмора, возникшей в рамках генеративной лингвистики. Как известно, в теории Ч. Филлмора падежная форма стала ассоциироваться с поверхностной структурой, собственно же падеж соотносился с так называемой глубинной структурой. «Глубинные» падежи, будучи искусственными по своему характеру, позволили выделить целый ряд «пространственных» падежей, широко представленных в исследовании Дж. Андерсена.

Несмотря на некоторую очевидность того факта, что формальные (поверхностные, падежные формы) и семантические (глубинные) падежи являются в сущности феноменами разного порядка, с точки зрения сопоставительно-типологического анализа ни формальный, ни семантический критерии к исследованию данной 
категории не могут быть признаны до конца удовлетворительными. Недостаток формального критерия к исследованию падежей, которые могли бы быть сопоставимы в разных языках, усматривается в явной непоследовательности их семантического обоснования. Это, во-первых, приводит к отсутствию конкретного основания межъязыкового сопоставления. Например, при сравнении таких языков, как русский и английский, в одном языке парадигма спряжения представлена шестью падежами, во втором - падежные формы применительно к существительному отсутствуют вообще или в крайне упрощенном виде свойственны только местоимениям. В то же время количество падежей в грузинском языке превосходит число падежей в русском языке. Во-вторых, одна и та же флексия существительного может функционировать в грамматическом значении разных падежей. Например, в русском языке флексия -у является формальным признаком и родительного, и винительного, и дательного падежей (из лесу, в лесу, похвала лесу), и тогда дистинктивной характеристикой падежа становится уже ударение. Флексия -е существительных женского рода также может выступать в значении как дательного (подарок школе), так и предложного падежей (Петя в школе). В-третьих, вполне естественно, что за необходимостью компенсировать отсутствие падежных отношений в языках возникают некоторые неточности их терминологического обозначения. Так, собственного дательного падежа, который представлен в русском языке, не существует ни в узбекском, ни в грузинском. В этих языках семантические функции датива оказываются шире, что находит свое отражение и в их обозначениях: дательно-направительный падеж в узбекском языке и дательно-винительный падеж (сокращенно ДВП) в грузинском языке.

Семантический же критерий к исследованию падежей, изначально призванный придать смысловую наполненность падежной категории, впал в известной степени в другую крайность, доведя количество возможных семантических - глубинных и пространственных - падежей до внушительной цифры, варьирующейся от языка к языку. При таком подходе проблемным моментом становится определение языковых средств актуализации падежа.

В исследованиях, выполненных преимущественно на материале аналитических европейских языков, наметился отказ от использования термина падеж. В аналитических языках смысловая функция падежей рассматривается в качестве семантики межобъектных отношений, актуализируемых предлогом. Таким образом, значение условного падежа и значение предлога оказываются равнозначными. Уже в работе Х. Педерсена каждому аффиксу финно-угорских языков соответствовал английский предлог. Так, венгерский hoz соотносился с английским towards и с категорией аппроксиматива, выражающего идею сближения, а венгерский nak ассоциировался с английским предлогом for и общей смысловой категорией датива (Реdersen, 1962: 246). В монографии М. Ерслунда французский предлог à и вовсе описывается как датив со всевозможными случаями его реализации и классификацией его значений (Herslund, 1988). В исследованиях же, выполненных на материале языков, в которых традиционная падежная форма по-прежнему передается флексией, предпринимаются попытки ассоциировать значение предлогов и сопутствующих им падежей (DurstAndersen, 2000). Эти и многие другие работы позволяют отметить удивительную тенденцию, связанную с морфемизацией падежей. Падеж выявляется не по казусной форме существительного и не по фиктивной актантной роли субъектно-объектных отношений, а по конкретной морфеме как минимально значимой единице языка. В одних языках падежную роль выполняют предлоги, в других - послелоги, в третьих - префиксы. Вместе с тем эти языковые единицы должны иметь собственное значение, внутреннюю форму.

Учитывая тот факт, что семантика морфемы передает смыслы, в которых заключены универсальные отношения, например, движение от предмета (к предмету), нахождение, принадлежность, попадающие под общую диалектическую категорию взаимодействия части и целого, то вполне очевидно, что морфологический критерий способен установить и некоторый базис для сопоставительно-типологического сопоставления. Сама же падежная категория становится своего рода моделью, или стратегией, имеющей прочный универсальный фундамент, свое внутреннее содержание, и варьирующейся от языка к языку. Представляется возможным определить этот основу в качестве когнитивно-типологической модели. Когнитивной, поскольку данный феномен связан с восприятием отношений, закладывающим определенный схематизированный ментальный образ. Типологической, так как семантика заданных отношений ассоциируется с универсалиями как на внутреннем, ментальном, так и внешнем, языковом, уровнях.

Когнитивно-типологическая основа датива. Как известно, одним из распространенных типов отношений, репрезентируемых условной падежной категорией, являются отношения, связанные с изменением положения субъекта или предмета в результате целенаправленного перемещения, воздействия на него, его передачи, смены его обладателя и т.п. Этот общий вид отношений может быть описан через датив как универсальную стратегию, как когнитивно-типологическую модель.

Приводя примеры из исландского языка, С. Эйнарсон отмечает, что датив употребляется при глаголах, обозначающих «быстрое движение» (цит. по: Svenonius, 2002: 2011). П. Свенониус, конкретизируя данный признак, соотносит значение датива в исландском языке с баллистическим движением, то есть с «движением объекта через пространство под воздействием кинетической энергии» (Svenonius, 2001: 3).

Движение и перемещение тесно взаимосвязаны с таким универсально-константным значением, как направленность. Определяя направленность как категориальное значение английской частицы to, относящейся к «числу локальных указателей направленности процесса на объект», И. Г. Кошевая соотносит данный элемент «грамматического инвентаря» с морфологической и синтаксической направленностью и дативностью как структурой. «Направленность предполагает совершенно определенную конечную точку своего развития, которая выступает ... замыкающей инстанцией определенного значения дативности ... Дативность 
предполагает наличие по меньшей мере двух (или более) объектов, спаянных определенной линией пространственного соотнесения, по которой идет целенаправленное перемещение какой-то части одного объекта к другому. Последнее предполагает непременное количественное тождество начальных и конечных долей, т. е. замкнутую перспективу движения, при которой весь объем отсеченной части первого объекта последовательно перемещается в расположение второго» (Koshevaya 2012: 101 - 102).

По свидетельству Г. А. Климова, термин «дательный падеж» становится обычной практикой применения в австралийских языках для обозначения единицы, также имеющей широкую направительную семантику (Klimov, 2009: 50).

Подобные исследования стали небезосновательной причиной рассмотрения движения вместе с перемещением и направленностью как прототипического параметра структуры датива, что связано со способом восприятия пространственных отношений, в результате которых объект, находившийся в некоторой точке пространства, в результате волевого действия оказывается в другой точке пространства.

Пространственная характеристика датива подчеркивается во многих исследованиях в его смысловой связи с местным падежом. В своей работе, посвященной реконструкции индоевропейского синтаксиса, К. Г. Красухин обнаруживает семантическое сходство между местным и направительным падежами, имеющими место в хеттском языке и которые рассматриваются исследователем как синоним дательного (Krasukhin, 2005: 66-67).

При определении движения (направления) крайне важным оказывается понятие перспективы, то есть ракурса оценки действия. Движение может восприниматься как совершающееся от близкого к далекому (прямая перспектива), так и от далекого к близкому (обратная перспектива). По мнению П. А. Дурст-Андерсена, дативу как раз соответствует реверсивное движение, предполагающее так называемую обратную перспективу (Durst-Andersen 2000).

Описывая особенность функционирования падежей и предлогов в ранний период существования английского языка, Б. А. Ильиш отмечает, что первоначально понятие пребывания в каком-либо месте выражалось самим дательным падежом, а предлоги местопребывания только уточняли это понятие (Ilyish 1968: 153). Употребление предлогов охватывает сферу как направленности к месту, так и пребывания в нем. Как следствие, дательный падеж, оказавшийся, очевидно, более конкурентоспособным по отношению к исчезнувшей форме местного падежа, принял на себя и значение местного падежа как часть своей смысловой структуры. Характер же датива оказывается не просто динамическим, а пространственно-динамическим в том смысле, что понятие пространства ассоциируется с местом. Этот детерминантный признак, находящийся на стыке конкурирующих падежей, задавая и конкретный языковой тип и составляя основу когнитивнотипологической модели, определяется как динамическое пространство.

Данный языковой факт находит свое отражение и в мировосприятии древнего человека, когда мир и все предметы в нем, как свидетельствуют многие мифологические источники, казались едиными. Впоследствии, когда предметы приобрели функциональную самостоятельность в сознании носителей языка, место единства, место совмещения предметов, вероятно, стало ассоциироваться с целью, а сам факт совмещения - с движением (перемещением с определенной целью). В связи с этим дательный падеж приобретает дополнительный оттенок движения к определенной цели, а падежом конкретного местопребывания становится предложный.

Используя семантические примитивы (Wierzbicka 1996: 35), употребляющиеся в ряде работ по описанию пространственной грамматики, представляется возможным определить формулу датива следующим образом: КТО-ТО (Y1) имеет ЧТО-ТО (Х) и делает ТО (V), в результате чего ЧТО-ТО (Х) есть часть КОГО-ТО (Y2) и больше не есть часть КОГО-ТО (Y1) или ЧЕГО-ТО (Y1). В данной формуле V обозначает глагол, Х представляет локализируемый объект, а Y - ориентир (релятум). В другом варианте расшифровки формулы Y соотносится с фоном, а X - с фигурой. В плане смысла Y актуализирует либо одушевленный предмет, либо предмет неодушевленный, но воспринимаемый как активный с точки зрения концептуализации пространственно-временных и функциональных отношений, либо местоположение, либо в более узком понимании - локальную точку. Данное местоположение символизирует функциональное единство предметов (cp.: Dobrushina 2001: 48) - ориентира и совмещаемого предмета.

С одной стороны, представляемое в настоящей работе понимание датива не связано с традиционным формальным падежом, свойственным целому ряду языков. С другой стороны, обозначение модели в рамках падежной терминологии не противоречит тому общему ментально-схематизированному представлению о дативе как категории, так или иначе имеющей место в большинстве языков. Таким образом, датив рассматривается как языковая универсалия. При этом обязательным условием становится идея его вербализации через конкретную морфему, а понимание датива как языковой универсалии оказывается связанным с феноменом морфологического датива.

\section{3. Актуализация датива как модели в разноструктурных языках}

3.1. Универсальный датив в английском и русском языках. Рассмотрим представленные выше теоретические обоснования на материале разноструктурных языков.

Что касается английского языка, то морфологическая единица, с которой может ассоциироваться датив, вполне очевидна. Морфемой-индикатором датива аналитического английского языка выступает предлог to. Здесь нельзя не упомянуть мнение М. Дейчбена об актуализации некоторого смыслового целого, обозначаемого дативом в предложениях типа: He came to London, This happened to him, complain to the magistrate, adhere to someone, The ancient Trojans were fools to your father, He behaved respectfully to her, You are like daughters to me, 
Bring me the book to me, I have bought a villa for my son, What's Hecuba to him, It is not easy for a foreigner to apprehend (Deuchbein, 1926). Приведем некоторые примеры из современного английского языка.

Классический случай актуализации датива представлен в примере (1): (1) Give this to the taxi dispatcher, Pasty, and he'll send you home (Hailey).

Диспетчер такси является бенефициантом. Сценарий описывается через глагол to give 'дать' и дативный предлог to: (2) Maggie stuck to Scotch (Susann). В примере (2) предлог tо используется в соответствии со своим назначением как предлог диалектического единства - единства Мэгги и скотча.

Сценарии, связанные с перемещением как достижением конечного пункта или объекта, актуализируются в следующих предложениях: (3) A waitress came to their table (Hailey); (4) Mel used the private elevator $<\ldots .>$ to descend from the tower to administrative magazine (Hailey).

Значение направленности в общем смысле может быть репрезентировано в следующих предложениях, которые повествуют об обращении капитана к пассажирам через использование многозначного глагола to put c предлогом to (5) и о направлении людей к границе аэродрома посредством употребления глагола направленности to direct с тем же предлогом to (6). (5) I hear the captain put it to the passengers (Hailey); (6) <...> pulling plows and men from the terminal area and directing them to the perimeter road (Hailey).

(7) Will you speak to Libby now? (Hailey)

В примере (7) актуализируется значение коммуникативной направленности, где роли объекта и адресата неразделимы.

(8) He recognized the speakerphone voice as belonging to a senior foreman $<\ldots>$ (Hailey).

В примере (8) описывается сценарий принадлежности. Голос принадлежит старшему бригадиру. Отношение голоса и бригадира представлено как отношение части к целому в их единстве.

Восприятие конечного объекта как эталона, как образа подражания (неподражания) находит отражение в семантической структуре предлога to как маркера датива: (9) He could peremptorily order an airline to remove a door sign which was misleading or faded to conform to terminal standards (Наiley). Предложение (9) демонстрирует условия соответствия стандартам терминала.

Экспериенциальное значение датива, передающее идею неизбежности перед обстоятельствами (ср., например, в русском языке мне приходится), являющееся неотъемлемой частью его семантической структуры, подчеркивает ключевую активную роль конечного объекта, участвующего в мнимом совмещении: (10) It occurred to him that he could use a map of February himself (Hailey).

Следующее предложение демонстрирует идею трансформации. (11) She had converted him to the English habit of tea at all times of the day <...> (Hailey). Прежний образ жизни без чайной паузы не пропадает как таковой, а трансформируется в привычку пить чай.

В русском языке классическому формальному дативу противопоставляется по морфологическому критерию глагольный префикс при-, отождествляемый с общей смысловой идеей функционального единства предметов.

В примере (12) представлена идея отношения предметов как части к целому - идея принадлежности, актуализируемая соответствующим глаголом с префиксом при-: (12) < .. > но так как воспоминания о Наталье Савишне <... п принадлежат к первой эпохе, скажу еще несколько слов о ней <... $>$ (Толстой)

Следует отметить, что помимо морфологической структуры слова, включающего в себя основу и префикс $n p u-$, естественным оказывается употребление и относящегося к глаголу существительного в форму классического датива с сопровождающим его предлогом $\kappa$.

Отношения совмещения, свойственные универсальному дативу, имеют широкий спектр реализации в русском языке посредством функционирования префикса $п р и$ - с глагольной основой.

(13) Я смотрел и чувствовал, что какая-то непонятная, непреодолимая сила притягивает мои глаза к этому безжизненному лииу (Толстой); (14) Мими стояла, прислонившись к стене, и, казалось, едва держалась на ногах <...> (Толстой); (15) Эта простая мысль отрадно поразила меня, и я ближе придвинулся к Наталье Савишне (Толстой).

В представленных выше примерах (13 - 15) обращает на себя внимание тот факт, что мнимая точка совмещения задается относительно того объекта, который описывает существительное, логически относящееся к nри- глаголу. Этими объектами соответственно выступают лицо (13), стена (14), Наталья Савишна (15). В этих примерах также, однако, глагольный префикс при- коррелирует с предлогом $\kappa$ и управляемым им существительным в традиционном дательном падеже.

Отношения, связанные с перемещением объекта в другую точку пространства, представлены следующими примерами.

(16) Наконец Мими пришла мне на помощь и почти насильно уложила в постель (Толстой); (17) На другой день у меня был жар довольно сильный и приехал наш добрый, старый Иван Васильевич < ...> (Толстой); (18) <..> персики во всем ивету, кой-где только остался снег, ласточки прилетели <...> (Толстой);(19) Бывало, прибежит ко мне, обхватит ручонками и начнет целовать и приговаривать (Толстой).

Основной особенностью данного типа отношений является то, что скорость, способ и средства перемещения не являются ключевым фактором при описании создаваемого в результате действия единства. Префикс при- актуализирует датив как модель, а глагольная основа детализирует характер перемещения. При этом для данного сценария характерен признак обратной перспективы восприятия перемещения, которое происходит издалека к наблюдателю. Исчезает и строгая привязка значения совмещения к формальному 
показателю дательного падежа в виде флексии. Представляется, что предлоги в и $к$ лишь конкретизируют параметры предметов, участвующих в совмещении с точки зрения их пространственного объема и возможности или невозможности быть помещенным один в другой.

3.2. Универсальный датив в агглютинативных языках. В узбекском языке, являющемся, как известно, языком агглютинативного типа, морфемой, репрезентирующей датив, выступает аффикс -ga, который соответствует маркеру традиционного дательно-направительного падежа. Учитывая тот факт, что образноментальная схема датива подразумевает идею направления с последующим совмещением объектов в одной точке пространства, в целях типологического исследования термин «направительный» кажется избыточным. Выведенная универсальная когнитивно-типологическая модель датива последовательно реализуется в узбекском языке через морфему-аффикс.

$(20)<\ldots>$ bir avliyo odam senga pichoq beribdi (Ахроров).

Пример (20) представляет собой самый общий и типичный для датива случай отношений, связанный с передачей предмета какому-либо лицу. Передача ножа определяет участника, выраженного местоимением «ты» («тебя» - senga) в роли извлекающего от действия пользу бенефицианта. Сценарий актуализируется глаголом bermoq 'дать' и морфемой-аффиксом -ga.

(21) Saparboy ozgina kechiksa Dilara mangulik olamiga o'tib ketadi (Ахроров); (22) <...> ba'zilari notanish kishilar orasidan o'tib kelgan Dilara asov ot arqonidan tutib turgan odamga dedi (Ахроров); (23) <...> yolg'iz Yaratganga ayon bo'lgan sirli $<\ldots>$ (Ахроров)

Различные виды направленности реализуются в представленных выше предложениях. Физическая направленность, выражающая такие значения как 'идти', 'ехать', 'приходить' и т. п. (21), коммуникативная направленность, подчеркивающая, как и английский предлог to, передачу мыслей, чувств, желаний (22), сентиментальная направленность, описывающая смысловые оттенки предрасположенности и антипатии, терпимости и нетерпимости, любви и ненависти в отношении того или иного объекта (23).

Что касается грузинского языка, то он также является агглютинативным языком, несмотря на довольно развитую систему конечных элементов структуры слова, позволяющих говорить о существительном как имеющем форму того или иного падежа. Классический маркер дм не определяет особенностей датива как потенциального падежа с сугубо собственным значением, так как в формальном дательном падеже грузинского языка оказывается возможным участие как косвенного объекта, так и прямого объекта действия. С другой стороны, достаточное языковое разнообразие получают оттенки движения, так, очевидно, и не получившие специального семантического ярлыка. Если принять во внимание семантическую проекцию датива, то его значение связано с обратной перспективой, то есть с движением от далекого к близкому, к наблюдателю. Как известно, в грузинском языке имеется специальный языковой элемент, обозначающий данный тип отношения. Этим элементом является послелог Әм. Именно с этим послелогом в системе грузинского языка может, на наш взгляд, ассоциироваться универсальная модель датива. Типовые примеры на употребление грузинского послелога Әм связаны с приближением субъекта к указанному месту:

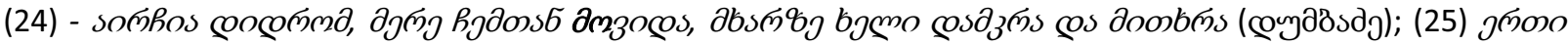

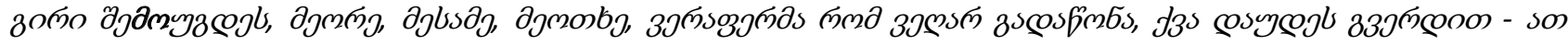

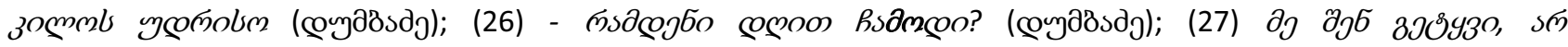

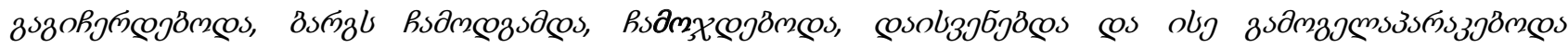

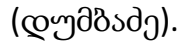

Ситуации, описывающие совмещение двух объектов в определенной точке пространства, определенно сближают в семантическом плане грузинский послелог $\partial м$ и русский префикс при-: приходить (24 - 25), приезжать (26), прибывать (27) и т.д.

Совмещение пассивного объекта с заданной точкой пространства, ассоциируемой с новым обладателем

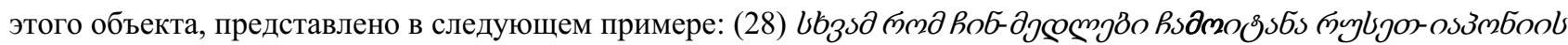

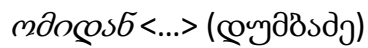

Глагольная форма с элементом $\partial м$ переводится как 'принесли'. Элементы же $\partial м$ и при также оказываются функционально и семантически сопоставимы друг с другом.

В глагольных формах грузинского языка, передающих общее значение движения от объекта, но содержащих элемент $\partial м$, подчеркивается идея осуществления действия с ракурса наблюдателя.

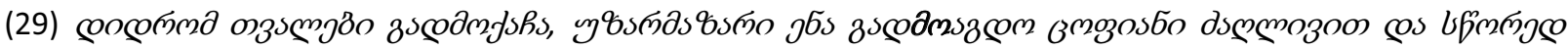

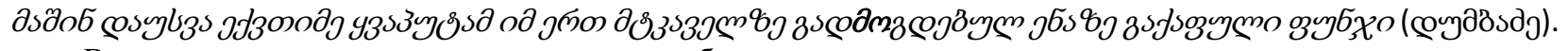

Выход, отправление человека, а также выброс предмета, вероятно, символизирует удаленность именно исходного пункта с достижением объектом локальной точки, в которой находится наблюдатель, описывающий событие.

Заключение и выводы. Эволюция научных представлений о падеже прошла этапы формального и семантического подходов, достигнув, наконец, и еще более конкретного морфосемантического подхода. Это свидетельствует об ощутимой тенденции к так называемой морфемизации падежных категорий.

Сопоставительно-типологическое исследование событийного фрагмента, ассоциируемого с дативом как моделью, было проведено на материале четырех разноструктурных языков - английского, русского, узбекского и грузинского. Датив как модель актуализируется не стандартными синтаксическими средствами в виде 
флексий, а конкретной морфемой, имеющей внутреннее смысловое содержание при передаче концепта отношений между предметами. Семантическая сеть морфемы каждого языка ассоциируется с дативом как универсальным падежом, в основе которого лежит представление о его когнитивно-типологической модели, включающей конкретные признаки, такие как функциональное единство предметов, направленность, реверсивная перспектива движения и т.д. В английском языке датив как модель репрезентирован предлогом в русском языке датив актуализирует маркер $n p u$, в основном функционирующий в роли глагольного префикса. В агглютинативных языках - узбекском и грузинском - датив ассоциируется с аффиксами $g a$ и $\partial{ }^{2}$ соответственно. Значение морфемы конкретизирует когнитивно-типологическую модель датива применительно к каждому языку, выявляя и сохраняя вместе с тем его общий смысловой базис.

Исследование, в результате которого было выявлено, что функторами стратегического датива выступают функционально разные языковые элементы слова - предлоги, приставки и аффиксы - способствует более глубокому изучению типологической структуры языков, дальнейшей разработке теории стадиальной и системной типологии и языковых типов. При этом в процессе анализа языковых типов за основу может быть взято не только на предложение как принципиальный маркер, определяющий тип языка, но и слово как «сжатая» модель высказывания.

\section{LIST OF REFERENCES}

Deuchbein, M. (1926). System der neuenglischen Syntax. Leipzig: Verl. von Teubner.

Dobrushina, Ye.R. (2001). Russkie pristavki: mnogoznachnost i semanticheskoe edinstvo [Russian prefixes: polysemy and semantic unity]. Moskva: Russkie slovari.

Durst-Andersen, P. V. (2000). Predlozhno-padezhnaya sistema russkogo yazyka. Ponyatie "contact vs. nekontakt" [Prepositionaland-case system of the Russian language. Concept "contact vs. no contact"]. Yazyki prostranstv. Logicheskiy analiz yazyka [Languages of space. Logical analysis of language]. Moskva: Yazyki russkoy kultury, 135-151.

Fillmore, Ch. (1968). The Case for Case. Universals in Linguistic Theory, 1-88.

Herslund, M. (1988). Le datif en français. Louvan-Paris: Editions Peeters.

Ilyish, B.A. (1968). Istoriya angliyskogo yazyka [A history of English]. Moskva: Vysshaya shkola.

Klimov, G.A. (2009). Printsipy kontensivnoy tipologii [Principles of contensive typology]. (2nd ed.). Moskva: Knizhniy dom «IBROKOM».

Koshevaya, I. G. (2012). Problemy yazykoznaniya I teorii angliiskogo yazyka: Chasti rechi i kategorii. Teoreticheskiy kurs [Problems of linguistics and theory of the English language: Parts of speech and categories. Theoretical course]. (2nd ed.). Moskva: Knizhniy dom «LIBROKOM».

Krasukhin, K.G. (2005). Ocherki po rekonstruktsii indoevropeiskogo sintaksisa [Essay on Indo-European syntax reconstruction]. Moskva: Nauka.

Pedersen, H. (1962). The discovery of language. (translated by J. W. Spargo). Bloomington: Indiana University Press.

Svenonius, P. (2001). Case and Event Structure. ZAS Working Papers, 26, 1-21.

Svenonius, P. (2002). Icelandic Case and the Structure of Events. Journal of Comparative Germanic Linguistics, 5, 197-225.

Wierzbicka A. (1996). Semantics. Primes and Universals. Oxford - New York: Oxford University Press.

\footnotetext{
Исследование выполнено при поддержке Городского общественного научно-экспериментального фонда «Языковая среда» (2. Рыбинск)
}

\section{For citation:}

Chernyshev, A.B. (2019) CASE MORPHEMIZATION AS THE BASIS OF ITS VIEWING WITHIN A COGNITIVE TYPOLOGICAL MODEL. International Scientific-Pedagogical Organization of Philologists “ WEST-EAST" (ISPOP). Scientific Journal WEST-EAST. Vol 1/1 N1 (October, 2019). pp.47-52. doi:

\section{Для цитирования:}

ЧернЫшев, А. Б. (2019) МОРФЕМИЗАЦИЯ ПАДЕЖА КАК ОСНОВАНИЕ ВЫЯВЛЕНИЯ ЕГО КОГНИТИВНОТИПОЛОГИЧЕСКОЙ МОДЕЛИ // International Scientific-Pedagogical Organization of Philologists “ WEST-EAST” (ISPOР) . Scientific Journal WEST-EAST. Vol 1/1 N1 (October, 2019). C. 47-52. doi:

Information about the author: Alexey B. Chernyshev - Candidate of Philological Sciences

Closed joint-stock company "VolgAero" (Rybinsk), Senior Interpreter;

Yaroslavl State Pedagogical University, Institute of Philology, Faculty of the Russian Language and Culture, Chair of Cultural Studies (Yaroslavl), Senior teacher;

Municipal Public Scientific and Experimental Foundation "Yazykovaya sreda" (Rybinsk), Chairman of Trustee Board

e-mail: alexeich78@mail.ru

Сведения об авторе: Алексей Борисович Чернышев - Кандидат филологических наук, Закрытое акционерное общество «ВолгАэро» (Рыбинск), старший переводчик;

Ярославский государственный педагогический университет им. К. Д. Ушинского, Институт филологии и культуры, факультет русской филологии и культуры, кафедра культурологии (Ярославль);

Городской общественный научно-экспериментальный фонд «Языковая среда» (Рыбинск), Председатель Попечительского Совета

e-mail: alexeich 78@mail.ru 